\title{
Perancangan dan Implementasi Virtualisasi Server Dengan Citrix Xenserver di PT. PLN Wilayah Semarang
}

\author{
Slamet Handoko \\ Politeknik Negeri Semarang \\ Jl. Prof. H. Soedarto, Tembalang, Semarang, Jawa Tengah, 50275 \\ hands101.polines@gmail.com
}

\begin{abstract}
Nowadays the need for information technology is growing rapidly, especially the need for a server as a medium for the passage of an application, in addition , there are constraints of the most important in the utilization of information technology at this time that the resource requirements are not cheap and space constraints, it is necessary utilization of resources as much as possible. Virtualization as a part of information technology is expected mamapu overcome the existing problems. If seen as part of an overall trend in a particular company PT. PLN (Persero) which use autonomic computing, a scenario in which wherein the IT environment will be able to manage itself based on perceived activity and utility computing, where processing power omputer considered a utility that clients can pay only used alone. Implementation of virtualization with Citrix XenServer based on Linux itself aims to centralize administrative tasks to improve scalability and also as part of the company's efficiency. The methodology used for this study is NDLC which has 6 phases namely, analysis, design, prototype simulation, implementation, monitoring and management, with the implementation of this system deiharapkan able to meet the needs of corporations.
\end{abstract}

Keywords-Virtualization, Server, Linux, Citrix, XenServer, $\mathrm{NDLC}$.

\section{Pendahuluan}

PT. PLN (Persero) merupakan perusahaan penyedia tenaga listrik di bawah kementrian BUMN, PT. PLN (Persero) Wilayah Bangka Belitung sendiri merupakan salah satu unit induk dari PLN Pusat, saat ini teknologi berkembang begitu cepat, pemanfaatan teknologi informasi mutlak harus dilakukan untuk mendukung proses bisnis dan untuk meningkatkan perfomance perusahaaan, begitu juga dengan PT. PLN (Persero) yang mana memiliki visi menjadi perusahaan dengan layanan kelas dunia (World Class Services).

Pada saat ini semua proses bisnis di PLN telah berbasis teknologi informasi, pengembangan teknologi informasi baik yang sifatnya core bisnis application maupun supporting application tentunya bertampak pada bertambahnya kebutuhan akan infrastruktur teknologi informasi dalam hal ini pengunaan layanan Server, penambahan software berbading lurus dengan pengadaan hardware (server), padahal terkadang kebanyakan perfomansi servisnya tidak lebih dari $20 \%$ saja. Hal ini menjadi pertanyaan bagaimana cara mengatasi permasalahan ini dengan mencoba sebuah teknologi baru.

Beberapa tahun terakhir ini banyak tipe processor yang mempunyai inti lebih dari satu terutama pada server processor dengan inti ganda, dengan melihat potensi processor yang mempunyai inti lebih dari satu tersebut, dapat kita manfaat kan untuk menjalankan aplikasi-aplikasi dan service secara bersamaan menggunakan teknik virtualisasi pada komputer server, dengan teknologi virtualisasi ini utilitas server dapat ditingkatkan sehingga perfomansi bisa meningkat secara signifikan dan yang lebih menarik dari teknologi ini adalah kemampuannya mendukung platform mesin server yang berbeda, sistem operasi yang berbeda dan banyak server di dalamnya dimana setiap server bisa berbagi resource dengan server lainnya, konsep cluster high availability yang terdapat pada virtualisasi server dapat mengurangi biaya dan menyederhanakan pengelolaan pelayanan teknologi informasi, implementasi teknologi virtualisasi yang memanfaatkan sumberdaya server secara maksimal diharapkan tidak menurunkan kinerja dari server .

Dengan teknologi virtualisasi diharapkan jumlah kebutuhan akan server menjadi berkurang dan masalah keterbatasan akan tempat menjadi lebih kecil, sehingga secara otomatis akan mengurangi biaya operasional server yang selama ini cukup mahal apakah dalam hal pengadaannya maupun pengoperasiannya, saat ini cukup banyak produk atau merk yang menawarkan teknologi Virtualisasi misalnya VMWare dengan Vsphere nya, akan tetapi harga yang ditawarkan untuk produk tersebut cukup tinggi dari license-nya, tentunya apabila kita melihat dari perspektif keuangan perusahaan, hal tersebut tidak efisien, oleh karena itu dalam skripsi ini akan kita bahas sebuah teknologi tanpa biaya atau open sources (free) dan mudah diimplementasikan dengan menggunakan XenServer Bare Metal Virtualization. 


\section{TINJAUAN PUSTAKA}

Pada bulan juni tahun 1959 seorang ilmuan computer asal inggris Christopher Strschey mempublikasikan paper yang berjudul Time Sharing in Large Fast Computers pada saat konferensi International Information Processing di UNESCO New York. Maksud dari konsep time sharing adalah bagaimana sebuah siste computer dapat berjalan secara Multi-Tasking dan Multi Programming. Pada Tahun 1960-an IBM menjalankan beberapa proyek yang bertujuan untuk mengevaluasi konsep time sharing system dan berhasil menciptakan mesin dengan konsep tersebut dengan memanfaatkan penuh mainframe hardware dengan cara membagi logical hardware kedalam mesin virtual, mesin yang berhasil diciptakan salah satunya adalah CP/CMS dan M44/44X yang menjadi cikal bakal dan arsitektur mesin virtual.

Dalam ilmu komputer, virtualisasi (inggris; virtualization) adalah istilah umum yang mengacu kepada abstraksi dari sumber daya computer, definisi lainnya adalah sebuah teknik untuk menyembunyikan karakteristik fisik dari sumber daya computer dan bagaiman system lain, aplikasi atau pengguna berinteraksi dengan sumber daya tersebut. Hal ini termasuk membuat sebuah sumber daya tunggal seperti server, sebuah system operasi, sebuah aplikasi atau peralatan penyimpanan terlihat berfungsi sebagai beberapa sumber daya logical atau dapat juga termasuk definisi untuk membuat beberapa sumber daya fisik (seperti beberapa peralatan penyimpanan atau server) terlihat sebagai satu sumber daya logical.

Istilah virtualisasi sudah digunakan secara luas sejak

tahun 1960-an oleh IBM untuk meningkatkan pemanfaatan system computer saat itu yang sangat besar dan mahal, namun saat ini telah diaplikasikan kepada beberapa aspek computer, dari keseluruhan system computer sampai sebuah kemampuan atau komponen individu. Bentuk lain pengertian Virtualisasi adalah metode untuk membuat sesuatu menjadi lepas dari ketergantungan secara fisik contoh : virtual machine adalah komputer, yang sebetulnya hanya berupa sebuah file di hardisk.Dengan virtualisasi, maka sebuah computer (fisik) bisa menjalankan banyak computer virtual sekaligus pada saat bersamaan. Secara sederhana adalah computer di dalam kompter, yang di implementasikan oleh software. Sebuah virtual machine mengemulasikan keseluruhan system hardware, mulai dari processor sampai network card, memungkinkan operating system yang berbeda untuk berjalan secara simultan, setiap system operasi berada pada partisi software yang berbeda secara bebas. Virtualisasi adalah penciptaan bentuk visual dari sesuatuseperti platform perangkat keras, system operasi, perangkat penyimpanan atau sumber daya jaringan.

Virtualisasi dapat dilihat sebagai bagian dari trend secara keseluruhan di perusahaan teknologi informasi dimana komunikasi yang mencakup komputasi otonom, sebuah scenario dimana lingkungan teknologi informasi dan komunikasi akan mampu mengelua sendiri didasarkan pada aktivitas yang dirasakan dan pengguna komputasi dimana kekuatan pemrosesan computer dipandang sebagai utilitas dimana klien dapat membayar jika diperlukan.

Terdapat tiga pendekatan virtualisasi, yaitu full virtualization, paravirtualization, dan hardware-assisted virtualization, namun menurut Jones, ada dua pendekatan virtualisasi lainnya yaitu hardware emulation dan operating system level virtualization. Perangkat lunak atau solusi yang melakukan virtualisasi kerap disebut sebagai Virtual Machine Monitor (VMM) maupun hypervisor. Dalam emulasi hardware, software virtualisasi biasa disebut hypervisor. Hypervisor merupakan perangkat lunak yang membuat mesin virtual dimana terdapat dua lapisan yakni mesin host dan mesin guest. Istilah mesin host mengacu kepada mesin tempat dibuatnya virtualisasi sementara istilah mesin guest mengacu kepada mesin virtual sendiri.

\section{Metode Penelitian}

Metode yang digunakan dalam pengembangan system ini adalah metode Network Development Life cycle (NDLC) dengan tahapan-tahapan yaitu: Analisis, Design, System, Simulasi, Implementasi, Manajemen dan Monitoring (James E. Goldman : 2005).

\section{A. Analisis}

Tahap analisis system adalah proses untuk mengumpulkan kebutuhan yang diperlukan serta alternative solusi yang dapat diteterapkan dalam penggunaan virtualisasi dengan menggunakan Citrix XenServer. Tahap awal ini dilakukan analisis keadaan system jaringan yang sedang berjalan, kemudian melakukan analisis system yang sedang berjalan dan kebutuhan akan system.

\section{B. Design System}

Perancangansistem merupakan langkah untuk menggambarkan hasil analisis baik system berjalan maupun system usulan. Dalam hal ini penulis melakukan perrancangan system virtualisasi pada server menggunakan Citrix XenServer, hal ini dilakukan untuk mempermudah dalam implementasinya. Untuk sistem jaringan yang digunakan saat ini adalah sebuah server yang terhubung WAN (Wide Area Network) melalui switch dan router.

\section{Simulasi Prototype}

Simulasi prototype sistem dilakukan ketika sistem yang diusulkan telah diterapkan pada sistem jaringan yang ada. Simulasi untuk menguji sistem yang telah diterapkan. Simulasi ini merupakan gambaran yang hamper sama ketika akan diterapkan dalam sebuah jaringan yang sesungguhnaya 


\section{Implementasi}

Implementasi atau penerapan merupakan langka untuk mengaplikasikan sistem baru yang telah disimulasikar Proses implementasi yang kan penulis lakukan adalah melipu instalasi Citrix XenServer pada server, Konversi Phisyci to Virtual pada server eksisting, membuat beberap virtualisasi/container yang masing-masing container memilik sistem operasi yang berbeda dan terakhi implementasi/koneksi jaringan masing-masing container.

\section{E. Monitoring}

Monitoring atau pengawasan merupakan langka setelah tahapan implementasi dan pengujian telah seles dilakukan. Pengawasan ini perlu dilakukan untuk untu menjaga agar virtualisasi yang telah di implementasika berjalan dengan baik.

\section{F. Management}

Management merupakan suatu pengaturan ata pengelolaan dalam menjalankan sistem virtualisasi Citrix XenServer yang telah di implementasi pada server, seperti membuat dan merubah user baru, melakukan kegiatan provisioning seperti membagi sumberdaya seperti kapasitas harddisk, memory dan processors, serta informasi resorce yang telah digunakan.

\section{HASIL DAN PEMBAHASAN}

\section{A. Kondisi Eksisting}

Sistem server eksisting masih mengandalkan penggunaan server-server fisik (physical server)

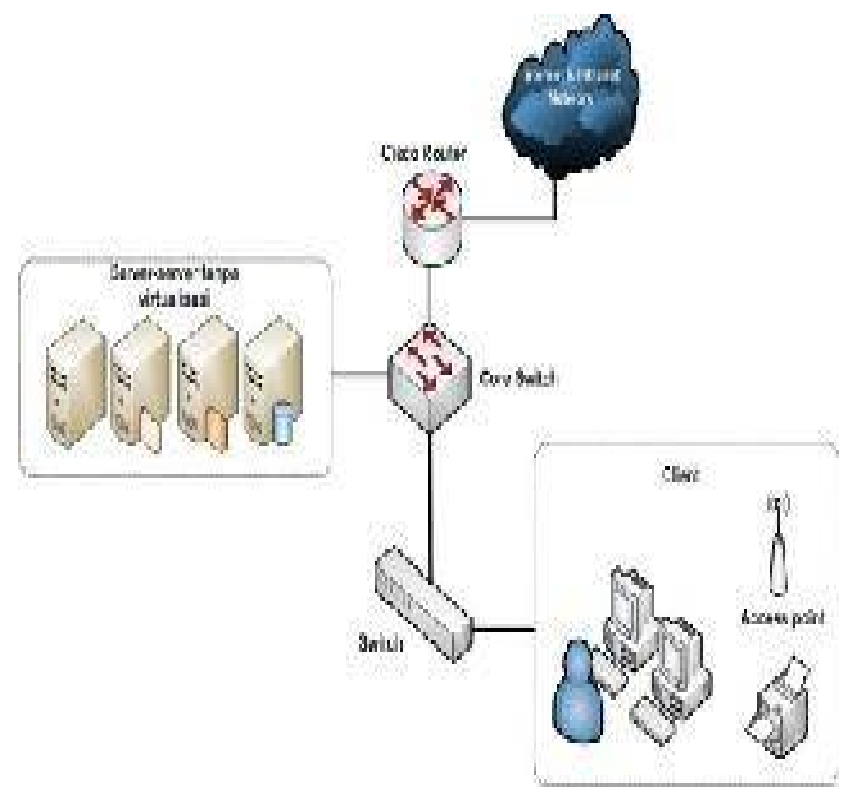

Gambar 1. Sistem Server Eksisting

\section{B. Design Sistem Usulan}

\section{Virtualization Defined}

For tixose more v sua $y$ inclinad.

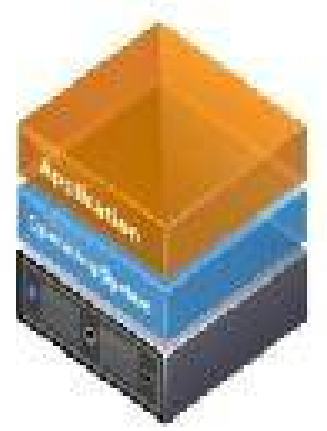

frodtaral arrbtowe

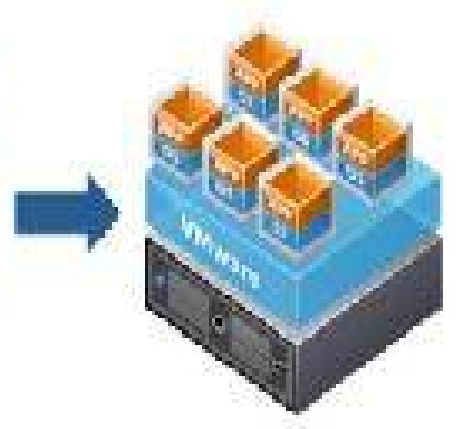

Whas anch tectu's
Gambar 2. Virtualization Defined

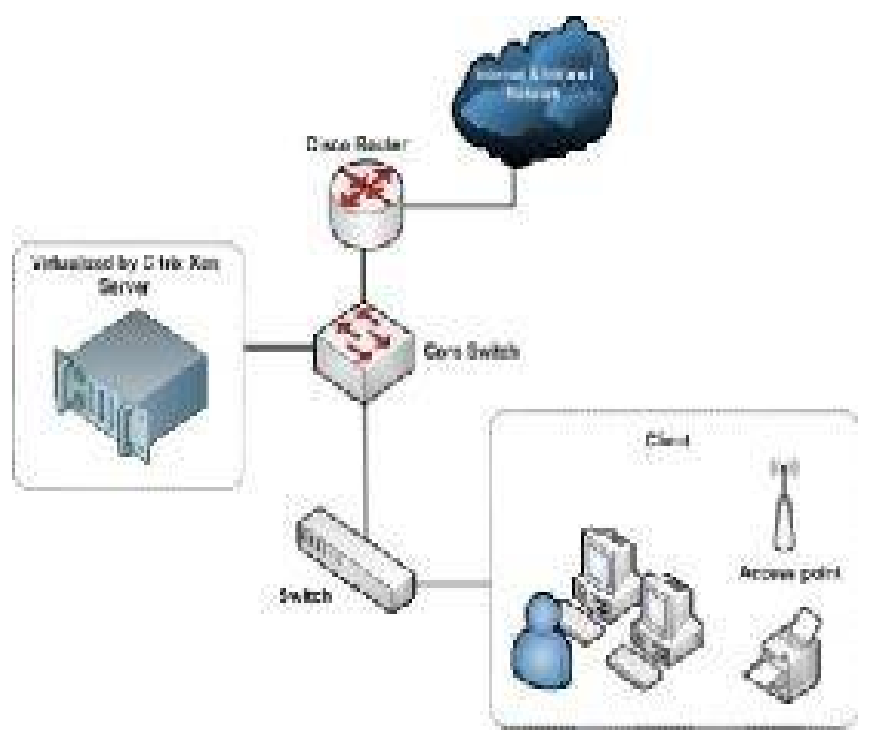

Gambar 3. Peta Design Sistem Usulan

Pada virtualization environment, server digabungkan dan berjalan dalam sebuah server, aplikasi-aplikasi tersebut diletakan pada sebuah server yang telah di virtualisasikan. Dengan menggunakan virtualisasi maka setiap aplikasi tetap memilki lingkungan dedicated walaupun berada dalam satu server.

\section{Citrix XenServer}

1) Citrix Console Interface 


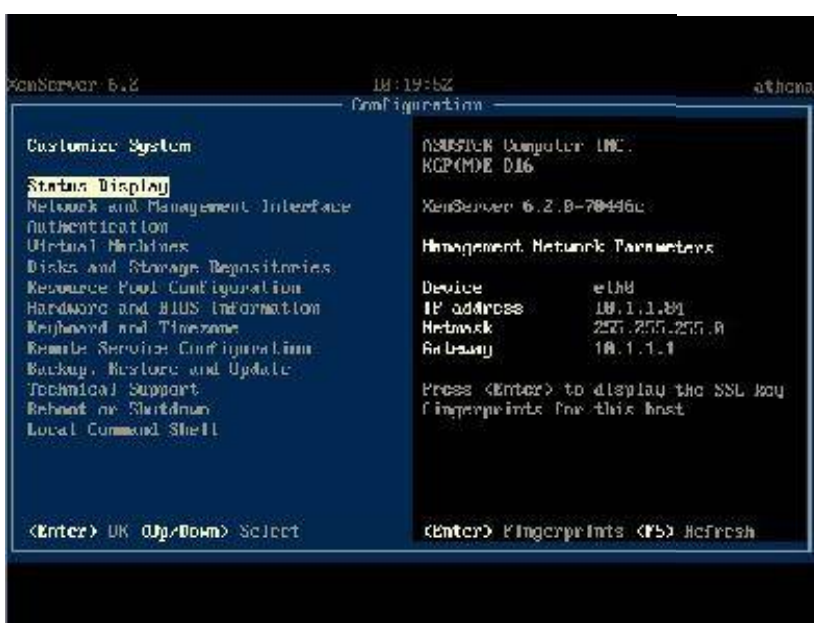

Gambar 4. Interface Citrix Console

\section{2) Citrix Management}

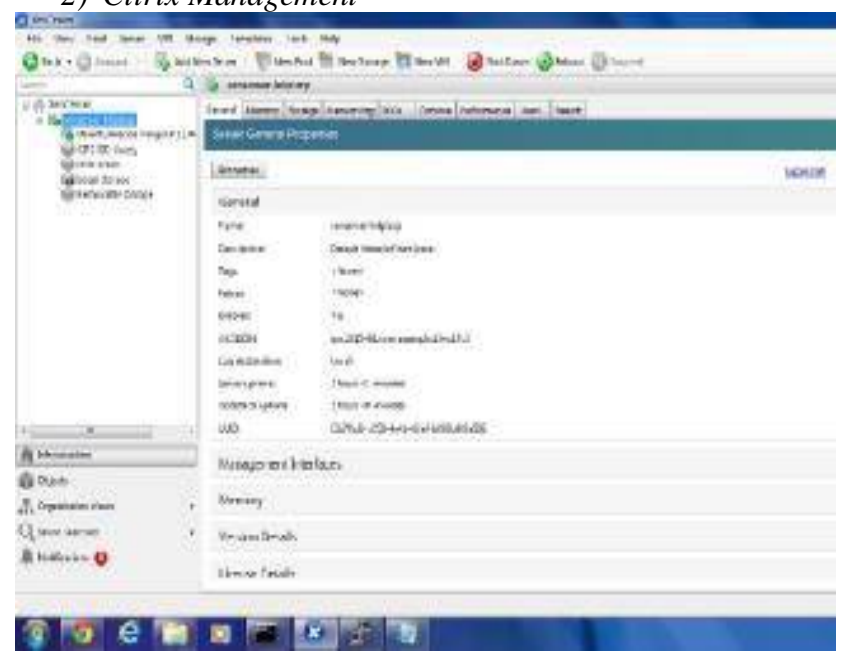

Gambar 5. Citrix Management

\section{Penutup}

\section{A. Kesimpulan}

Dari penelitian ini dapat ditarik kesimpulan sebagai berikut:

- Virtualisasi merupakan sebuah perkembangan dalam dunia teknologi informasi yang dapat membatu kita dalam pemanfaatan sistem computer dan sumber dayanya semaksimal mungkin.
- Dengan menggunakan teknologi virtualisasi maka dapat mengurangi pengadaan server, karena beberapa aplikasi yang membutuhkan lingkungan dedicated dapat diletakan pada satu server.

- Tingginya kebutuhan pengguna akan layanan teknologi informasi berbanding lurus dengan bertambahnya permintaan akan server, dengan virtualisasi pada server maka dapat menghemat tempat untuk meletakan server tersebut.

- Dengan menggunakan Citrix XenServer kita dapat memisahkan kita dapat memisahkan aplikasi kita ke mesin virtal yang berbeda yang benar-benar independen dari satu sama lain, tetapi masih menggunakan hardware yang sama, hal ini dapat menghemat dalam pengeluaran uang dalam hal pengadaan server dan mengurangi konsumsi daya listrik yang dipakai.

- Dengan virtualisasi proses backup sistem akan menjadi lebih mudah dan cepat

\section{B. Saran}

Teknologi virtualisasi dengan Citrix XenServer ini masih jauh dari sempurna dan masih banyak keurangan. Oleh karena itu perlu dilakukan pengen bangan dan penyempurnaan lebih lanjut, Adapun saran agar sistem ini bisa berfungsi dengan lebih optimal adalah :

- Citrix XenServer merupakan sebuah sistem opensource sehingga masih ada beberapa beberapa modul yang belum mendukung kebutuhan sistem secara maksimal akan tetapi secara keseluruhan sudah dapat mengakomodasi kebutuhan server pada umumnya.

- Pada PT. PLN (Persero) Wilayah Bangka Belitung sebagai sebuah perusahaan yang kebutuhan akan layanana teknologi informasi yang selalu bertambah, virtualisasi menjadi solusi untuk mengatasi kendala tingginya biaya pengadaan server.

\section{DAFTAR PUSTAKA}

[1] Ashari, Ahmad, dkk. 2010 Linux Sistem Administrasi. Bandung: Informatika.

[2] Pratt, Ian. 2006. Xen and the Art of Virtualization P. O'Rourke and M.Keefe.2001. Perfomance Evaluation of Linux Virtual Server.

[3] Sutanta, Edhy. 2005. Komunikasi Data \& Jaringan Komputer. Yogyakarta: Graha Ilmu.

[4] W.Purbo, Onno. 2008. Panduan Mudah Merakit dan Menginstal Server Linux. Yogyakarta : Andi.

[5] Zhang. W.1999. Linux Virtual Server for Scalable Network Service. 